\title{
An Algorithm for Transmission Distance Relay Setting Calculation Under Network Topology Change
}

\author{
Oktay Arikan ${ }^{1}$, Ozgur Gursanli ${ }^{2}$, Hidayet Aydin ${ }^{3}$, E. Alptekin Yagmur ${ }^{4}$ \\ Yildiz Technical University, Electrical Engineering Department, Istanbul, Turkey ${ }^{1}$ \\ Tubitak Marmara Research Center, Energy Institute, Kocaeli, Turkey ${ }^{2,3,4}$
}

\begin{abstract}
Power systems are being expanded day by day with a more complex structure. The system topology always changes due to faults and/or operation requirements. Therefore; malfunctions might occur in the protection system which is one of the most important components for the system reliability, stability and economic operation. Distance protection relays fulfil the main protection function of the power transmission lines. In this study, an algorithm is created which recalculates the distance protection relay setting values depending on the topological changes of the network. The algorithm verified by testing on a selected area from the Turkish National Power Transmission System which comprises $154 \mathrm{kV} 28$ buses. Modelling of the power system carried out with Dig silent Power factory software. The algorithm is created in the DPL (Dig silent Programming Language) platform.
\end{abstract}

Keywords: Transmission line protection, distance relay, topology change, Dig Silent DPL script.

\section{INTRODUCTION}

The numbers of generation units are increasing with the rapid growth in energy demand. Due to the subsidized of renewable energy generation, especially the new generation units are added to the system from different locations [1]. System topology changes continuously due to the addition of new generation units, transmission lines and switching operations. For this reason, some changes will happen in traditional power system operation [2-4]. Today, it should be considered that multiple switching actions cause the changes on the system operation [5]. Furthermore, cascading events caused by different faults can cause multiple switching actions [6]. Different load shedding and switching cases are done to ensure the reliability of the protection system and power system stability, keep voltage within certain boundaries and reducing operating costs [7-10]. So that, alterations on the system topology raises the need of change the distance protection relay coordination settings [11-14].

Faults, power fluctuations, voltage instabilities and load encroachments are conditions that can lead to missoperation to relays. In order to prevent the miss-operations of relays the zone setting should be calculated correctly and updated after the topology changes. The operation of distance protection relays is important in terms of system stability under abnormal conditions, especially in case of power swing and fault. Topology changes affect the power swing behaviour [15]. Power swings create significant fluctuations in system voltage/current magnitude and angle so it causes to change of the load impedance. These fluctuations can cause to misoperation of the distance relays [16-17].

Due to 'Load encroachment' feature, even if there is any short circuit fault, it may be happen wrong trippings at overloaded lines [18]. In case of overload, load impedance value gets smaller in accordance with $\mathrm{Z}=\mathrm{V} / \mathrm{I}$ formula. Distance relay generates trip signal when the load impedance value is smaller than the predetermined zone settings. So, while the adjustments of the distance protection relay zone settings, the maximum load impedance also should be considered [18-19].

In this study, an algorithm which recalculates the zone settings in case of system topology changes is created for the distance relays which are used the main protection of transmission lines. The algorithm is based on the Turkish National Power Transmission System defence plan methodology. The algorithm is validated by testing a 154 $\mathrm{kV}$ pilot area of Turkish National Power Transmission System which comprises 28 buses. DigSilent Power Factory software is used for the analysis performed on the transmission system model and the creation of DPL algorithm. The results obtained by 3 -phase fault analysis are presented as a case study.

\section{ZONE SETTING CALCULATIONS OF DISTANCE RELAY}

Distance, over current and differential relays can be used for protection of transmission lines. However, distance relays are mostly used for main protection of transmission lines. Distance relay basically determines the line impedance by comparing the voltage and current values according to equation $\mathrm{Z}=\mathrm{V} / \mathrm{I}$. If the measured impedance value of relay is smaller than the previously entered relay zone setting then relay operates and generates trip signal. Distance protection relays have different type of characteristics such as impedance, reactance, mho and quadrilateral. In this study, a mho type distance relay 
which has 3 stages forward zone and 1 stage reverse zone is examined.

There are two different ways to calculate the settings of distance protection relays zones. One is based on line impedance, other is based on the apparent impedance of line. Under study, line impedance values are used for calculations of zone settings [20].

Distance protection relay zone setting values are calculated according to the following rules:

- Zone $1=0.85 \times \mathrm{Z}_{\mathrm{l}}$ : Set to $85 \%$ of the protected line impedance, no time delay to trip.

- Zone $2=\mathrm{Z}_{\mathrm{l}}+0.5 \times \mathrm{Z}_{\mathrm{sl}}$ : Set to $100 \%$ of the protected line impedance $+\% 50$ of the next shortest adjacent line impedance, $400 \mathrm{~ms}$ time delay to trip.

- $\quad$ Zone $3=\mathrm{Z}_{\mathrm{l}}+\mathrm{Z}_{\mathrm{ll}}$ : Set to $100 \%$ of the protected line impedance $+\% 100$ of the next longest adjacent line impedance, $800 \mathrm{~ms}$ time delay to trip.

- Reverse Zone $=Z_{\mathrm{r}}$ : Set to longest reverse line impedance, $1.5 \mathrm{~s}$ time delay to trip.

- Where; $Z_{\mathrm{l}}$ is protected line impedance, $Z_{\mathrm{sl}}$ is shortest adjacent line impedance, $Z_{l l}$ is longest adjacent line impedance and $Z_{r}$ is longest reverse line impedance.

Relay zones shown in Figure 1.

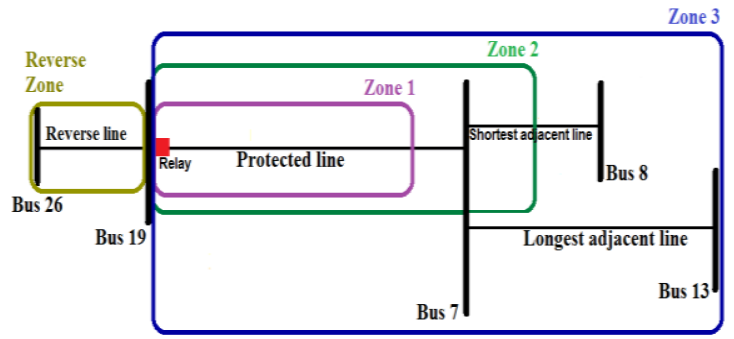

Fig.1Relay zones

\section{CALCULATION ALGORITHM}

The proposed algorithm recalculates the zone settings considering out of service lines, end of service lines or new added lines. The calculated new values are saved automatically in the relay. Thus, it is provide to avoiding the miss-operations due to the topology change. It is possible to calculate the zone settings quickly for different models and different types of relays. The over-all flow chart of the created algorithm is shown in Figure 2.

The input data for algorithm includes:

- System topology (buses, lines, bus connections)

- Line parameters ( lengths, impedances, resistances, reactances, line angles)

- Protection devices (relays, current transformers, voltage transformers).

Firstly, the algorithm finds the entire distance protection relays in the system. After that, it determines the protected line from related relay and next bus. Then it finds the all connected lines to the next bus except protected line. These lines are called adjacent lines. Within the connected lines, the shortest line is assigned as "shortest adjacent line" and the longest line is assigned as "'longest adjacent line" by the algorithm. Line parameters of these assigned lines are used to calculation of forward zone settings.

For the calculation of reverse zone setting, the algorithm finds the lines except protected line which are connected the protected bus. The longest one is assigned as "reverse longest line'. Reverse longest line parameters are used for the calculation of the reverse zone settings.

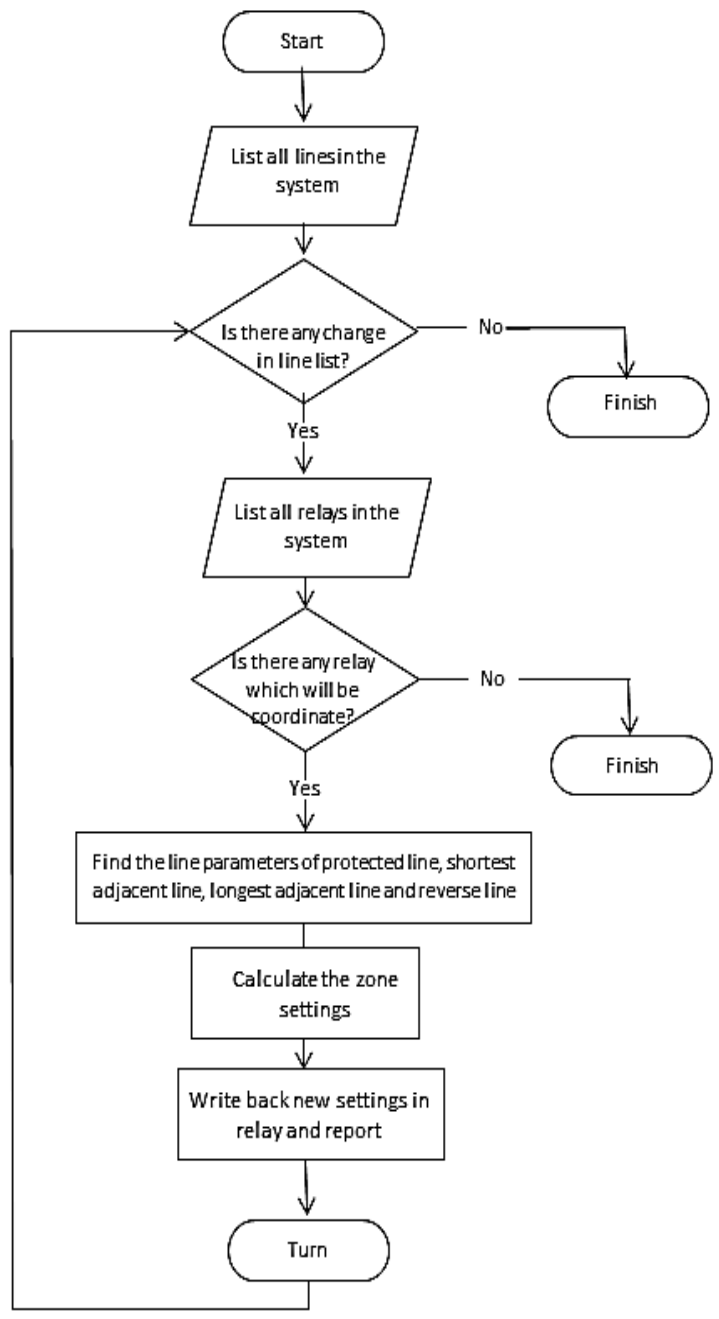

Fig.2 General flow chart of algorithm

\section{CASE STUDY}

The created algorithm for this study is applied to the 28 bus system which is a part of the Turkish National Power Transmission System. Figure 3 shows the single-line diagram of the bus system which is created in Digsilent software. The analyses are performed for 3-phase fault conditions on Bus7-Bus9 line.

Automatic calculation algorithm is created with the Digsilent programming language (DPL) software. Also modelling of Mho type distance protection relay and fault analyses are carried out with Digsilent Power factory software.

The algorithm is tested to considering two different cases ofanalysis. 


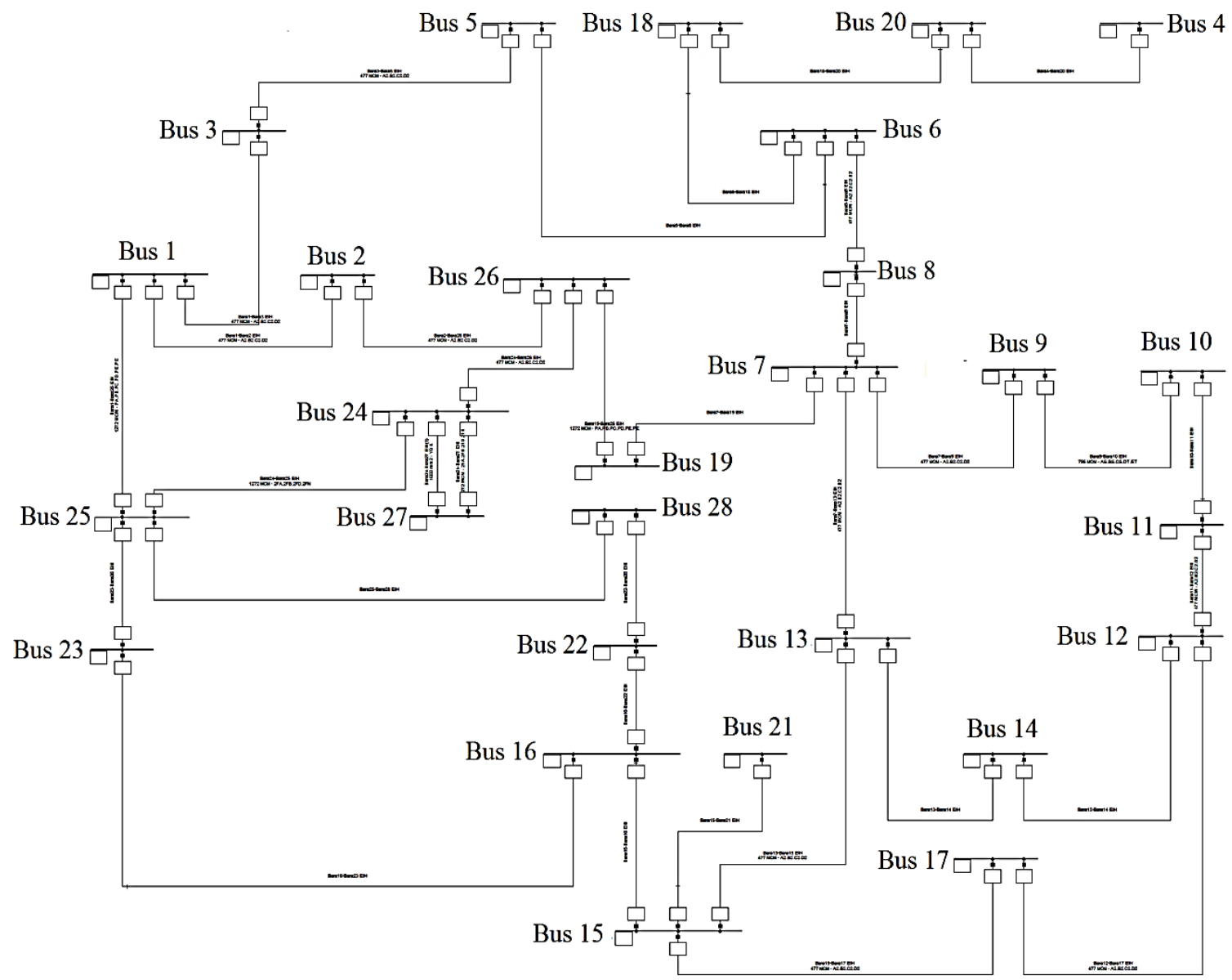

Fig. 3 Single line diagram of 28 bus system

At the first case, calculation is performed using the existing network structure. At the second case, a scenario is considered that Bus7-Bus9 line is being out of service due to a fault.

A. Relay Coordination Study in Case of Existing Topology.

In the first case, analyses are performed using the existing network structure which is shown in Figure 4. The algorithm is run for the Mho characteristic relay which is connected the Bus19. The relay protects the Bus19-Bus7 line. Thenzonesettingsofrelay are calculated. Relay gets the current information froman 800/5.

A current transformer and voltage information from a $154 / 0.100 \mathrm{kV}$ voltage transformer. The protected line, adjacent lines and fault location are shown in Figure 4.At the first case, calculation is performed using the existing network structure. At the second case, a scenario is considered that Bus7-Bus9 line is being out of service due to a fault.

The lines which have been used in the calculation relay zone settings are listed below:

- $\quad$ Protected line: Bus19-Bus7 line

- Shortest adjacent line: Bus7- Bus8 line

- Longest adjacent line: Bus7- Bus13 line

- Reverse line: Bus19- Bus26 line.

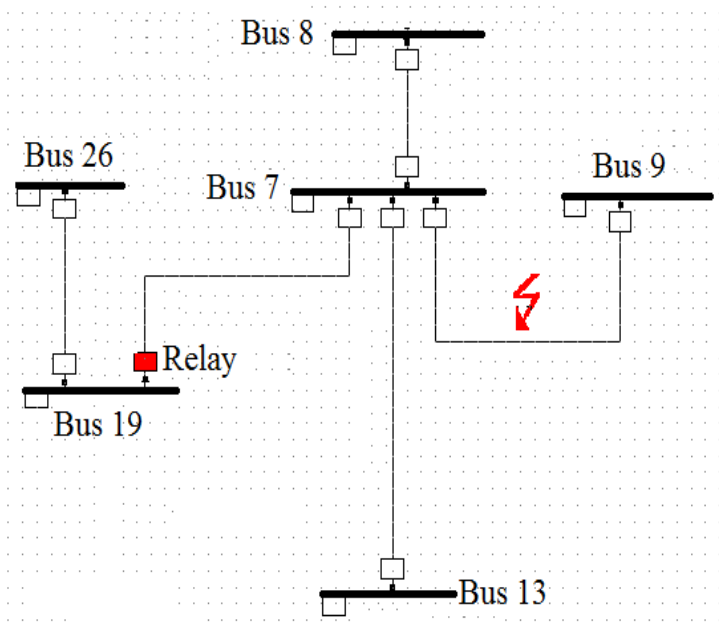

Fig.4 Single line diagram of existing topology and fault location

The parameters of the lines are given in Table 1.

TABLE I: LINE PARAMETERS

\begin{tabular}{|l|l|l|l|l|}
\hline Lines & $\begin{array}{l}\text { Length } \\
(\mathrm{km})\end{array}$ & $\begin{array}{l}\mathbf{R}_{\Omega} \\
(\mathrm{ohm})\end{array}$ & $\begin{array}{l}\mathbf{X}_{\Omega} \\
(\mathrm{ohm})\end{array}$ & $\begin{array}{l}\mathbf{Z}_{\Omega} \\
(\mathrm{ohm})\end{array}$ \\
\hline Bus8-Bus7 & 18.5 & 2.48 & 7.97 & 8.35 \\
\hline Bus7- Bus19 & 48.4 & 2.52 & 21.21 & 21.35 \\
\hline Bus7- Bus13 & 49.8 & 6.69 & 21.46 & 22.48 \\
\hline Bus7- Bus9 & 37.6 & 5.05 & 16.21 & 16.97 \\
\hline Bus19- Bus26 & 52.2 & 2.72 & 22.85 & 23.01 \\
\hline
\end{tabular}


INTERNATIONAL JOURNAL OF INNOVATIVE RESEARCH IN ELECTRICAL, ELECTRONICS, INSTRUMENTATION AND CONTROL ENGINEERING Vol. 4, Issue 5, May 2016

The zone settings of distance relay installed at Bus19 which are obtained from calculation results are shown in Table 2.

\section{TABLE II: ZONE SETTINGS AT EXISTING TOPOLOGY}

\begin{tabular}{|c|c|}
\hline Zones & $\begin{array}{c}\text { 3-Phase Zone } \\
\text { Settings } \\
\text { (sec.ohm) }\end{array}$ \\
\hline Zone 1 & 1.91 \\
\hline Zone 2 & 2.69 \\
\hline Zone 3 & 4.58 \\
\hline $\begin{array}{c}\text { Reverse } \\
\text { Zone }\end{array}$ & 2.24 \\
\hline
\end{tabular}

A 3-phase short circuit fault is performed at the Bus7Bus9 line. The R-X diagram of the relay is shown in Figure 5. The fault impedance seen by relay is 2.881 sec.ohm and fault angle is $81.81^{\circ}$. Short circuit fault is seen in Zone 3 and relay generates $0.84 \mathrm{~s}$ time delayed tripping signal. The obtained results indicate that relay fulfills the its function as expected.

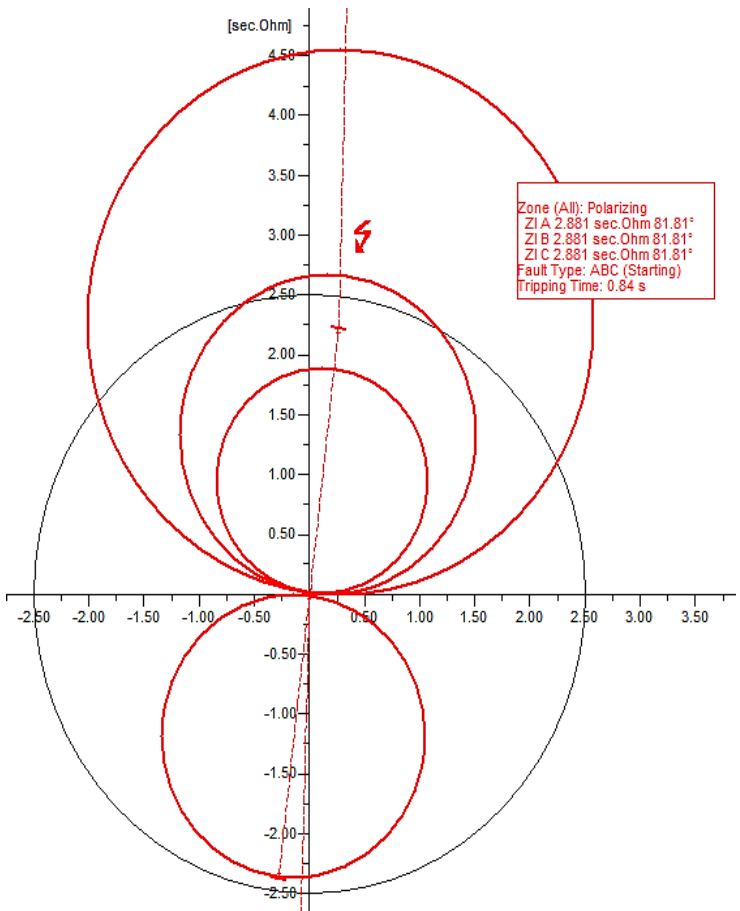

Fig.5R-X Diagram of the relay

B. Relay Coordination Study in Case of Topology Change In the second case, a scenario is made for reconfiguration which may occur in the network. Bus7-Bus8 line is deactivated for the topology change scenario as shown in Figure 6 .

A 3-phase fault condition is repeated for new topology with existing relay settings at same location between Bus7-Bus9 line. The fault should be seen in Zone 2 according to the new structure of the network. Despite the changes of the topology relay see the fault in Zone 3 again due to existing settings. As seen in Figure 7. fault impedance is $2.73 \mathrm{sec} . \mathrm{ohm}$ and angle is $81.77^{\circ}$ degrees.

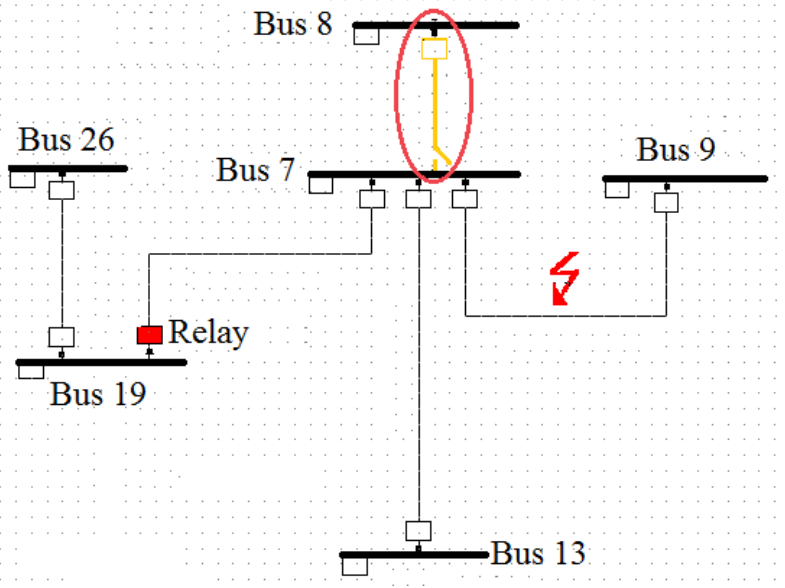

Fig.6Single line diagram after topology change

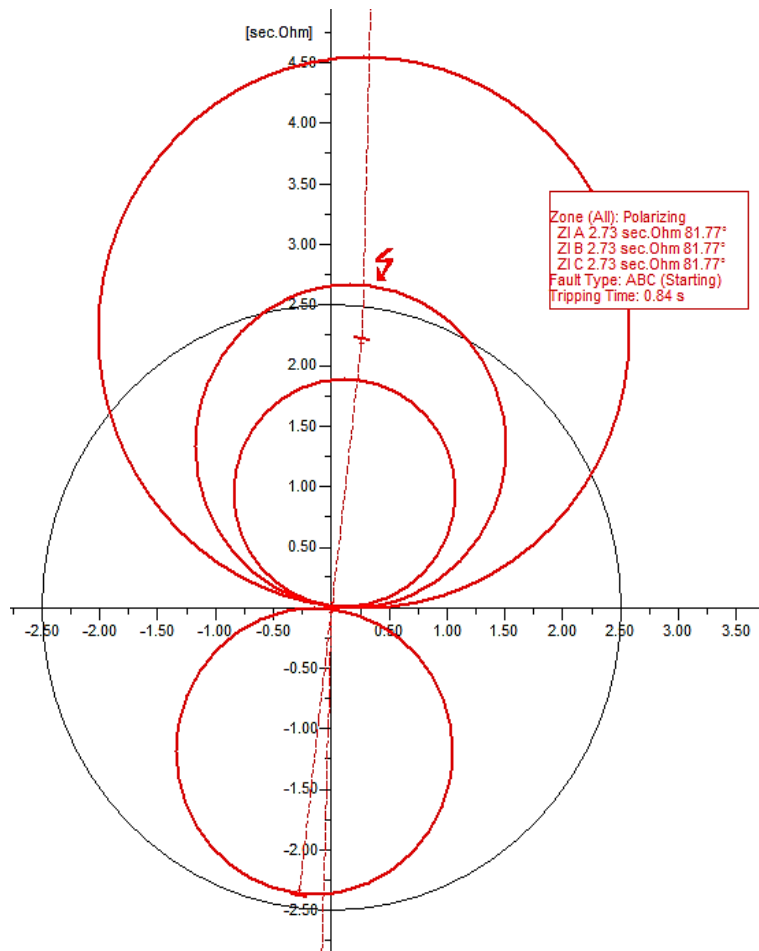

Fig.7R-X diagram of changed topology with existing settings

This case shows that when the impact of topology change is not reflecting to the zone settings, then relay can't perform its task properly. The obtained results reveal that topology changes cause incorrect trippings.

It is possible to elimination of undesirable situations via to reflect the change of the relay settings in case of the network reconfiguration. Using the proposedalgorithm relay zone settings are recalculated according to the changed topology.

For the calculation of Zone 2, in the existing topology Bus7-Bus8 line is the shortest adjacent line but after topology change Bus7-Bus9 line is being the shortest adjacent line. Because of this reason it is seen that after recalculation Zone 2 setting value increased from $2.69 \mathrm{sec} . \mathrm{ohm}$ to $3.12 \mathrm{sec} . \mathrm{ohm}$ due to the topology change. The recalculated zone settings are given in Table 3 . 
INTERNATIONAL JOURNAL OF INNOVATIVE RESEARCH IN ELECTRICAL, ELECTRONICS, INSTRUMENTATION AND CONTROL ENGINEERING Vol. 4, Issue 5, May 2016

TABLE III: ZONE SETTINGS AT THE SECOND CASE

\begin{tabular}{|c|c|c|}
\hline Zones & $\begin{array}{c}\text { Existing } \\
\text { Topology } \\
\text { Settings } \\
\text { (sec.ohm) }\end{array}$ & $\begin{array}{c}\text { Changed } \\
\text { Topology } \\
\text { Settings } \\
\text { (sec.ohm) }\end{array}$ \\
\hline Zone 1 & 1.91 & 1.91 \\
\hline Zone 2 & 2.69 & 3.12 \\
\hline Zone 3 & 4.58 & 4.58 \\
\hline $\begin{array}{c}\text { Reverse } \\
\text { Zone }\end{array}$ & 2.24 & 2.24 \\
\hline
\end{tabular}

The new zone settings are entered in relay. After that, the same analysis has been performed and relay response is tested. A 3-phase short circuit fault is occurred same location at the Bus7-Bus9 line.

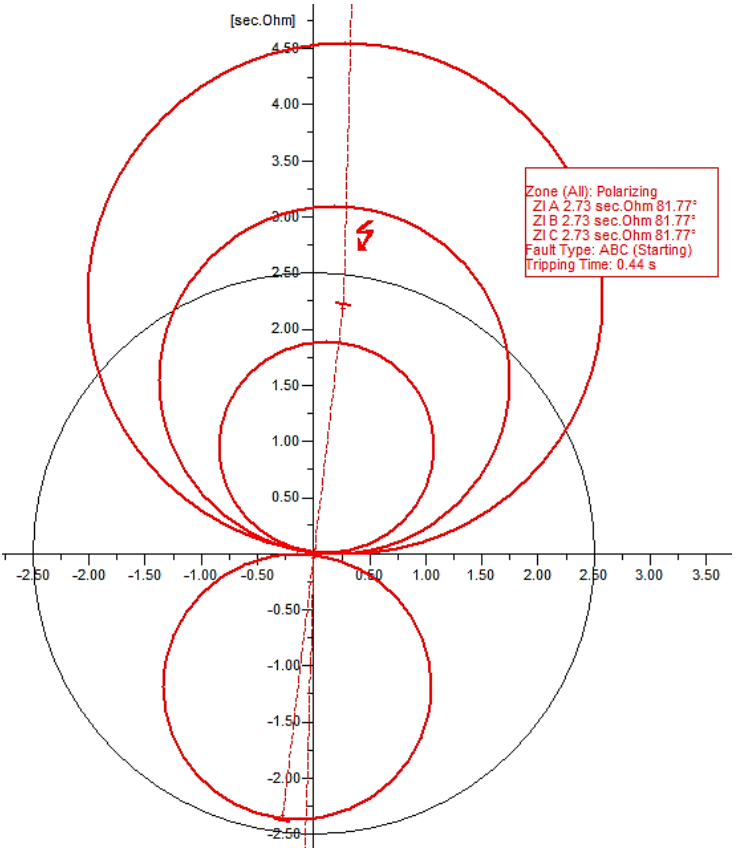

Fig.8R-X diagram of changed topology

It is indicated that fault impedance is 2.73 sec.ohm and angle is 81.70. The R-X diagram is shown in Figure 8. In this case the fault is seen in Zone 2 and relay generates a $0.44 \mathrm{~s}$ time delayed trip signal. The results demonstrate that algorithm works correctly and relay detects the fault at right zone thanks to entering the new zone settings.

\section{RESULTS AND DISCUSSIONS}

Distance relays may give incorrect tripping signal due to the network topology changes. Change in the network topology causes changes in the zone settings of distance relays. For this reason, an algorithm has been created which recalculates the relay setting values when the network topology is changed. The proposed algorithm determines the protected line, shortest adjacent line, longest adjacent line and reverse line again based on the location of protective relays. It calculates the zone settings for the relays according to the determined lines.

To examine the effect of structural changes on the relay setting values, Bus7-Bus8 line out of service scenario is investigated. It is shown in Figure 9. that Zone 2 setting value increased from 2.69 sec.ohm to 3.12 sec.ohm due to topology change.

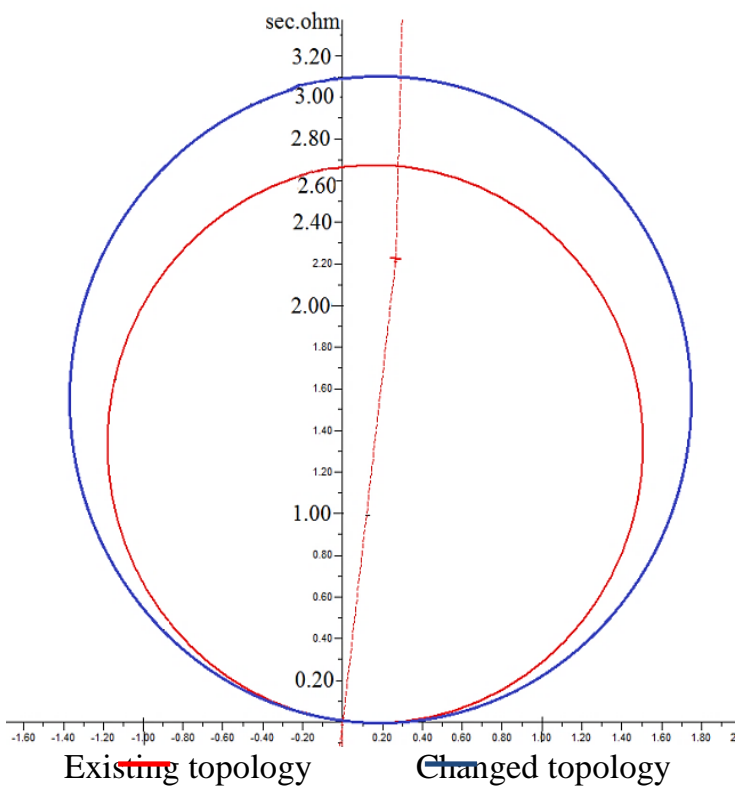

Fig.9 R-X diagram of Zone 2

The performance of the distance relay is tested with the existing settings and the settings created by proposed algorithm for a 3-phase fault condition. When the relay settings aren't arranged according to the new topology, the fault is seen in Zone 3. But, it has to be seen in Zone 2 . For the new system topology, relay detects the fault in Zone 2 when the recalculated zone settings are entered in relay. It is shown that relay generates correct tripping time by using the new settings. In this case, the duration of fault clearance decreased. Consequently, it will be provided to prevent triggering the cascading events and/or damaging the equipments.

\section{CONCLUSION}

Network topology is changing for reasons such as adding new lines in to the system, being out of service of the lines caused by faults and removing the lines from network. These changes effect the proper functioning of the relay. In order to prevent the miss-operations of the distance protection relays, the zone setting values have to be calculated correctly and should be updated according to the changing system conditions. In this study, an algorithm is described in Digsilent Power factory which recalculates the zone settings when the network topology changes.

Algorithm is implemented in a part of Turkish National Power Transmission System which is consisting of $154 \mathrm{kV}$ 28 buses. The performance of the algorithm is tested for 3phase fault conditions by a selected relay in the region. Relay tripping signals are controlled for different scenarios. Obtained results show that topology changes need to be considered for the safely and continuously operation of power system. The proposed algorithm is successfully able to determine the correct settings for the new topology of the system. 


\section{REFERENCES}

[1]. Z. Chen, "Issues of Connecting Wind Farms into Power Systems," IEEE Transmission and Distribution Conference \& Exhibition, 2005.

[2]. I. J. Pérez-Arriaga and C. Batlle, "Impacts of Intermittent Renewables on Electricity Generation System Operation," IIT Working Paper, January 2012.

[3]. Jonathan D. Rose and Ian A. Hiskens, "Challenges Of Integratıng Large Amounts Of Wind Power," Annual IEEE Systems Conference, 2007 1st Hawaii, vol., no., pp.259,265, 9-12 April 2007.

[4]. Kai Heussen, et al., "Unified System-Level Modeling of Intermittent Renewable Energy Sources and Energy Storage for Power System Operation," IEEE SYSTEMS JOURNAL,vol.6, no.1,pp. 140-151, March 2012.

[5]. Adolfo R. Escobedo, Erick Moreno-Centeno and Kory W. Hedman, "Topology Control for Load Shed Recovery," IEEE TRANSACTIONS ON POWER SYSTEMS, vol. 29, no.2, pp. 908916, March 2014.

[6]. M. Bagriyanik, et al., "Assessment of protection Relay Coordination in Turkish National Power Transmission System to Prevent Cascading Events," APAP2009, October 18-21, 2009.

[7]. Qixin Chen, et al., "Modeling Flexible Operation Mechanism of O2 Capture Power Plant and Its Effects on Power-System Operation," IEEE TRANSACTIONS ON ENERGY CONVERSION, vol. 25, no. 3, pp. 853-861, September 2010.

[8]. Jonathan A Kelly, "Power system operation and control design for combined geothermal and wind diesel power generation on Nevis, West Indies," GEOTHERMAL TRAININGPROGRAMME, Number 17, Reports 2012, 2012.

[9]. K. W. Hedman, S. S. Oren, and R. P. O'Neill, "Optimal Transmission Switching:Economic Efficiency and Market Implications," Journal of Regulatory Economics, vol.40, no.2, pp.111-140, 2011

[10]. CamilaFernandes, et al., "Impact of Vehicle-to-grid on Power System Operation Costs-The Spanish Case Study," Applied Energy 96, pp. 194-202, 2011.

[11]. Hui Wan, K. K. Li and K. P. Wong, "An Adaptive Multiagent Approach to Protection Relay Coordination With Distributed Generators in Industrial Power Distribution System," IEEE TRANSACTIONS ON INDUSTRY APPLICATIONS, vol. 46, no.5, pp. 2118-2124, September-October 2010.

[12]. AydoganOzdemir, et al., "Impacts of protection system misoperation on the reliability of Turkish National Power Transmission System," The International Conference on Advanced Power System Automation and Protection, vol., no., pp. 619-623, 2011

[13]. A. S. Noghabi, et al., "Considering Different Network Topologies in Optimal Overcurrent Relay Coordination Using a Hybrid GA," IEEE TRANSACTIONS ON POWER DELIVERY, vol. 24, no.4, pp. 1857-1863, October 2009.

[14]. M. Kezunovic, et al., "Reliable Implementation of Robust Adaptive Topology Control," International Conference on System Sciences (HICSS), 2014 47th Hawaii, vol., no., pp.2493,2502, 6-9 Jan. 2014.

[15]. S. A. Soman, et al., "Analysis of angle stability problems: a transmission protection systems perspective," IEEE Trans. Power Del., vol.19, no.3, pp.1024,1033, July 2004.

[16]. Laurie Martuscello, et al., "Tests of distance relay performance on stable and unstable power swings reported using simulated data of the August 14th 2003 system disturbance," 62 ${ }^{\text {nd }}$ Annual Conference for Protective Relay Engineers, vol., no., pp. 236-255, 2009.

[17]. H. K. Zadeh and Zuyi Li, "A novel power swing blocking scheme using adaptive neuro-fuzzy inference system," Electric Power Systems Research 78 (2008), vol., no., pp. 1138-1146, September 2007.

[18]. Ming Jin and Tarlochan S. Sidhu, "Adaptive load encroachment prevention scheme for distance protection," Electric Power Systems Research 78 (2008), vol., no., pp. 1693-1700, 2008.

[19]. Ab. H. Abu Bakar, et al., "Analysis of overload conditions in distance relay under severe system contingencies," Electrical Power and Energy Systems 32 (2010), vol., no., pp. 345-350, 2009.

[20]. M. Tasdighi and M. Kezunovic, "Impact Analysis of Network Topology Change onTransmission Distance Relay Settings,” 2015 IEEE Power \& Energy Society General Meeting, 26-30 July 2015.

\section{BIOGRAPHIES}

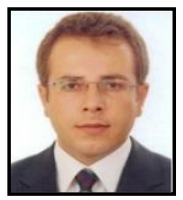

OktayArikanis working as an Assistant Professor Dr. at the Electrical Engineering Department of Yildiz Technical University, Turkey.He received his $\mathrm{BSc}, \mathrm{MSc}$ and $\mathrm{PhD}$ degrees all in electrical engineering from Yildiz Technical University /Turkey in 2001, 2003, and 2009, respectively. His research interests are power systemsanalysis, high voltage engineering and power quality.

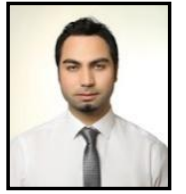

Ozgur Gursanli is a Researcher at Tubitak Marmara Research Center Energy Institute. $\mathrm{He}$ is MSc student at Yildiz Technical University /Turkey. He received his BSc degree in electrical engineering from Istanbul Technical University /Turkey. His current research interests are power transmission system protection, and power system analysis.

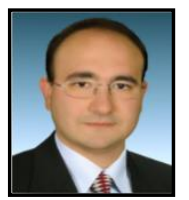

HidayetAydin is a Researcher at Tubitak Marmara Research Center Energy Institute. $\mathrm{He}$ is MSc student at Yildiz Technical University /Turkey. He received his BSc degree in electrical engineering from Yildiz Technical University /Turkey. His current research interests are power transmission system protection, and power system analysis.

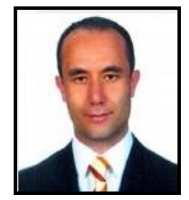

E. Alptekin Yagmur is working as a Senior Researcher at Tubitak Marmara Research Center Energy Institute. He received BSc and MSc degrees in electrical engineering from Istanbul Technical University /Turkey in 1996 and 2001, respectively. His research interests are renewable energy systems, power systems analysis and power quality. 